\title{
Safety Distance of Helical Energy Dissipation Device for Concrete Mortar Gravity Pipeline Transportation in Deep Shaft
}

\author{
L.C. Jiang ${ }^{1,2}$, Y.Q. Zhang ${ }^{1,2}$, and H. Z. Jiao ${ }^{3 *}$ \\ ${ }^{1}$ Institute of Safety Science and Engineering, South China University of Technology, Guangzhou 510640, China \\ ${ }^{2}$ School of Civil Engineering and Transportation, South China University of Technology, Guangzhou 510640, China \\ ${ }^{3}$ School of Civil Engineering, Henan Polytechnic University, Jiaozuo 454003, China
}

Received 7 September 2020; Accepted 30 December 2020

\begin{abstract}
Vertical transportation of concrete mortar is essential to the deep shaft lining strength and construction efficiency. The helical energy dissipation device (HEDD) for mortar's high potential energy control in the vertical pipe of gravity transportation is invented to control the accelerated flow, pipeline wear, and mortar segregation. To avoid the prediction deviation of helical pipe pressure loss, an HEDD predicting model was established by adopting a correction coefficient $\lambda$. The relationship of safety distance among the HEDDs was deduced on the basis of full pipe flow theory. The influences of parameters, namely, diameter $d$, pipe and helix diameter ratio $d / D$, screw pitch $s$, flow velocity $v$, and safety distance $H_{0}$ were analyzed by the HEDD predicting model on a deep shaft. Results show that the safety distance among the adjacent dissipation devices is negative to parameters $d, d / D$, and $s$. While the safety distance is positive to $v$, which was verified by Fluent software. The suggested optimal parameters of HEDD are a screw pitch of more than $1.50 \mathrm{~m}$, a pipeline diameter of $219.0 \mathrm{~mm}$, and a safety flow velocity of $0.50-0.75 \mathrm{~m} / \mathrm{s}$. The HEDD avoids concrete segregation, reduce pipeline wear, and improve lining quality. The conclusions obtained in this study can provide an alternative approach for high-speed construction of a deep shaft.
\end{abstract}

Keywords: Shaft construction, Concrete mortar, Gravity transportation, Helical energy dissipation device, Safety distance

\section{Introduction}

The shaft is the throat for the deep mining operation [1-2]. The quality of concrete lining plays a significant role in the service life of the shaft [3-5]. The popular methods of concrete mortar transportation are the bucket intermittent transportation and the pipeline gravity continuous transportation. The bucket approach remains an ongoing challenge because of its low efficiency and intricate process. The pipeline method has attracted extensive interest in the large transportation capacity and high efficiency. But some problems, such as serious slurry segregation and pipeline wear, exist in deep well transportation.

Adding spiral energy dissipation device in the process of straight pipe transportation is an important way to control slurry flow rate and reduce pipeline wear. The spacing among the devices has become an important design parameter in adding spiral energy dissipation device in straight pipe. However, the concrete mortar with high potential energy in the vertical pipeline will lead to slurry segregation and pipe wear, which is severely detrimental to the shaft lining quality [6-8]. Introducing helical energy dissipation device (HEDD) in a vertical pipeline is an attempt to increase mortar flow resistance and avoid segregation. Interestingly, the safe distance among the adjacent devices is the critical parameter to the dissipation device. The pipeline is easily blocked by mortar when dissipation devices are aligned closely; otherwise, the flow

*E-mail address: jiaohuazhe@126.com

ISSN: 1791-2377 @ 2020 School of Science, IHU. All rights reserved. doi:10.25103/jestr.136.10 velocity cannot be effectively limited when dissipation devices are arranged loosely.

Therefore, it is crucial to accurately determine the safe distance among the HEDDs for the gravity pipeline transportation design.

\section{State of the art}

In recent years, the pipeline wear has been discussed mainly in the field of mining backfill slurry transportation. The literature concludes that the wear is due to the non-full pipe flow states. For example, Liu et al. established a mathematical expression of the relationship among pipe diameter, flow velocity, and full pipe flow based on the theory of two-phase pipe flow; they also provided a principle for the selection of system delivery parameters [9]. Zhang et al. researched the impact wear of non-full-flow pipelines and analyzed the wear position and mechanism of backfill drillhole [10]. Cooke optimized the parameters of deep mine filling pipeline based on the theory of full pipe flow [11]. Hewitt et al. ranked various wear control methods based on relative wear resistance and energy loss per unit mass [12]. $\mathrm{Wu}$ et al. studied the resistance characteristics of structure fluid backfilling slurry in pipeline transport under full-flow transport in deep mine backfilling [13-16].

The discussion on energy dissipation device is mainly from the field of hydraulic engineering and rarely involves deep shaft concrete conveying. For example, Wang et al. studied the effect of particles with different mechanical properties on the energy dissipation properties of concrete [17]. Zhang and Ai studied the relationship between 
the energy loss coefficient and the influencing factors of the sudden reduction and enlargement energy dissipater using numerical simulation methods [18]. Fossa and Guglielmini provided the accurate prediction models for pressure drop analysis by analyzing the thin and thick singularity pressure [19]. Bullen et al. analyzed the effect of the shrinking pipe structure on the loss coefficient based on fluid mechanics [20], and $\mathrm{Wu}$ et al. studied the transport resistance characteristic of paste pipeline considering the effect of wall slip and the mortar rheological parameters in gravity transport [20-23]. The utilization of spiral energy dissipation devices to solve the problem of vertical pipe gravity concrete transportation has not been reported yet.

This study proposes the technical scheme of adding an HEDD in the vertical pipe to eliminate the high potential energy of concrete mortar. An HEDD model is constructed, and the expression of resistance loss is derived by the correction coefficient $\lambda$. The safety distance of adjacent devices is studied on the basis of full pipe flow theory. The influences of factors, such as the internal structure of devices and slurry flow parameters, on the safety distance of a deep shaft construction project are calculated and analyzed. The research results will provide a new method for the concrete pipe gravity transportation in the deep shaft.

The rest of the paper is organized as follows. Section 3 gives the proposed method. Section 4 presents the results and discussion in detail, and the conclusions are summarized in Section 5.

\section{Methodology}

\subsection{Helical energy dissipation predicting model}

The concrete mortar flow state in gravity pipeline transportation is shown in Fig. 1(a). The accelerating flow will be formed at pipeline entrance due to potential energy of concrete mortar. The free-falling subject continuously scours the wall to cause pipe wear. When the potential energy is equal to the resistance, the slurry movement state becomes full pipe flow with an increase in depth [23]. At the interface between the accelerated flow and the full-flow pipe section, the tremendous change in velocity will considerably affect the pipe wall. Thus, the interface is the most severe location for pipeline wear. Adding an HEDD can increase the resistance to achieve full pipe flow transportation in the entire pipe and reduce pipeline wear, as shown in Fig. 1(b).

\subsection{Model construction}

The potential energy of the concrete mortar in the deep shaft will go beyond the energy consumption capacity of single energy dissipation device. Therefore, several HEDDs are arranged in the vertical pipe in a certain spacing, as shown in Fig. 2. The safety distance among the adjacent HEDDs is $H_{0}$, the dissipation device height is $H_{1}$, the screw pitch is $s$, the screw diameter is $D$, and the diameter of the concrete transporting pipe is $d$.

The theoretical assumptions of this study are given as follows: (1) The concrete mortar is regarded as an incompressible fluid, and the fluidity characteristics follow the Bingham model. (2) No time-varying characteristic is considered during transporting, and the viscosity is a constant value. (3) The influence of vibration and heat exchange in transportation is ignored.

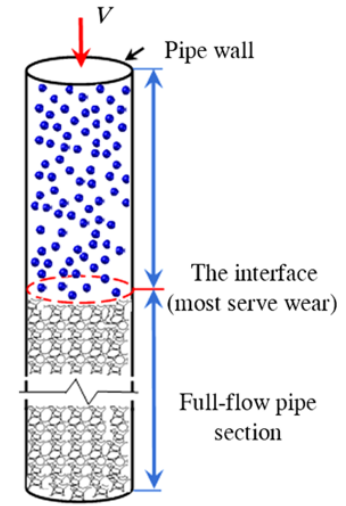

(a) Non-full

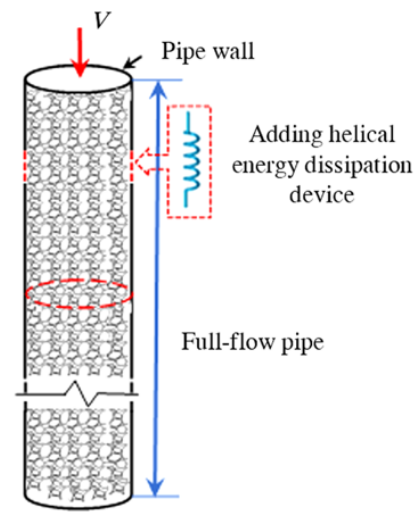

(b) Full
Fig. 1 Transportation state of two pipe flow transportations.

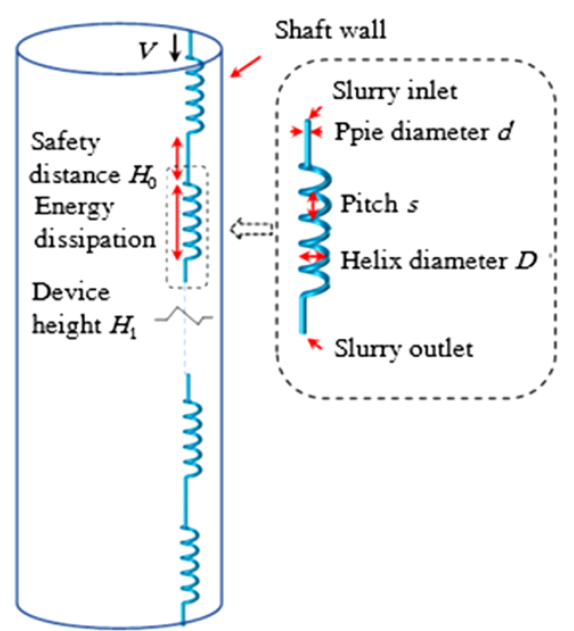

Fig. 2 Transportation model of HEDD.

\subsection{Resistance analysis}

The energy dissipation device can increase the pipeline resistance to the full pipe flow transportation states. The safety distance of HEDDs is determined from the required resistance. Concrete mortar is a non-Newtonian fluid, which follows the Bingham fluid rheological model [24], as shown in Eq. (1).

$$
\tau=\tau_{0}+\mu \gamma
$$

where $\tau$ is the shear stress, Pa. $\tau_{0}$ is the yield stress, Pa. $\mu$ is the plastic viscosity, Pa's. $\gamma$ is the shear rate, $1 / \mathrm{s}$.

The frictional loss coefficient of the vertical pipe transportation [25] is

$$
i_{m}=\frac{16}{3 d} \tau_{0}+\frac{32 v}{d^{2}} \mu
$$

where $i_{m}$ is the resistance loss, $\mathrm{Pa} / \mathrm{m} . v$ is the concrete flow velocity, $\mathrm{m} / \mathrm{s} . d$ is the pipe diameter, $\mathrm{m}$.

In the helical pipe transportation, the mortar will form a secondary flow phenomenon in a direction perpendicular to the conveying direction. The pipe transportation resistance will increase significantly [26]. A resistance correction coefficient $\lambda$ is introduced to characterize the relationship between the resistance of the spiral pipe and the straight pipe resistance. The expression of the modified resistance coefficient of the helical pipe is 
$i_{\mathrm{h}}=\lambda\left(\frac{16}{3 d} \tau_{0}+\frac{32 v}{d^{2}} \mu\right)$

\subsection{Determination of correction coefficient}

According to Dean et al. [27-28], the resistance of the helical pipe transportation is related to the Reynolds number Re and the pipe and helix diameter ratio. Supposing the correction coefficient $\lambda$ is a function of $\operatorname{Re}$ and , that is,

$\lambda=f(\operatorname{Re}, d / D)$

Under the condition of full pipe flow, the flow speed of concrete in the deep shaft pipe is slow and in the laminar flow state. Therefore, the influence of Reynolds number on the resistance can be ignored; the correction factor $\lambda$ can be regarded as a function of the pipe and helix diameter ratio $d / D$.

$$
\lambda=f(d / D)
$$

As shown in Table 1, six pipes and helix diameter ratio are selected for comparative analysis of the functional relationship between the correction coefficient and the pipe and helix diameter ratio. The resistance is calculated by numerical methods.

The C50 concrete is widely used for deep shaft lining construction; the rheological parameters are shown in Table 2 [29-30].

Table. 1. Pipe and helix diameter ratio of the project.

\begin{tabular}{c|c|c|c}
\hline No. & Pipe diameter $\boldsymbol{d} / \mathbf{m}$ & Helix diameter $\mathbf{D} / \mathbf{m}$ & $\boldsymbol{d} / \boldsymbol{D}$ \\
\hline 1 & 0.10 & 2.0 & 0.05 \\
2 & 0.10 & 1.0 & 0.10 \\
3 & 0.15 & 1.0 & 0.15 \\
4 & 0.20 & 1.0 & 0.20 \\
5 & 0.50 & 2.0 & 0.25 \\
6 & 0.30 & 1.0 & 0.30 \\
\hline
\end{tabular}

Table 2. C50 concrete rheological properties parameter.

\begin{tabular}{c|c|c|c|c|c|c}
\hline \multicolumn{3}{c|}{ Mixture ratio } & Density $\rho\left(\mathrm{kg} / \mathrm{m}^{3}\right)$ & \multicolumn{2}{c}{ Rheological properties parameter } \\
\hline $\begin{array}{c}\text { Cement } \\
1.00\end{array}$ & Coarse aggregate & Fine aggregate & Water & 2400 & $\begin{array}{c}\text { Yield stress } \tau_{0}(\mathrm{~Pa}) \\
200\end{array}$ & Viscosity coefficient $(\mathrm{Pa} \cdot \mathrm{s})$ \\
\hline
\end{tabular}

The numerical simulation in this study is conducted by Fluent software with Laminar flow model. The pipeline inlet adopts the velocity boundary, and the pipeline outlet adopts the pressure boundary. The material characteristic follows the Bingham Model. The relationship between the correction coefficient $\lambda$ and the pipe and helix diameter ratio can be obtained from Table 3 .

Table 3. Resistance of various pipe and helix diameter ratios.

\begin{tabular}{c|c|c|c}
\hline No. & $d / D$ & $(\mathrm{~Pa} / \mathrm{m})$ & $\lambda$ \\
\hline 1 & 0.05 & 36908.85 & 3.56 \\
2 & 0.10 & 39557.93 & 3.81 \\
3 & 0.15 & 41194.82 & 3.97 \\
4 & 0.20 & 42397.14 & 4.08 \\
5 & 0.25 & 43353.84 & 4.18 \\
6 & 0.30 & 44151.52 & 4.26 \\
\hline
\end{tabular}

As shown in Fig. 3, the functional relationship between the correction coefficient $\lambda$ and the pipe and helix diameter ratio is

$$
\lambda=4.82\left(\frac{d}{D}\right)^{0.1}
$$

\subsection{Safety distance among energy dissipation devices}

The distance among the adjacent HEDDs essentially determines the pipeline flow state. The dissipation devices installed in the large distance cannot provide sufficient resistance to balance the gravity potential energy that forms full pipe flow condition. Excessive quantity dissipation devices will lead to enormous resistance in the pipeline. This condition easily causes pipe plugging accident and then causes pipeline overpressure or even pipe explosion, which will affect the construction safety of deep shaft. Therefore, the distance among the adjacent HEDDs is the safety distance , which can ensure the full pipe flow and avoid slurry blockage.

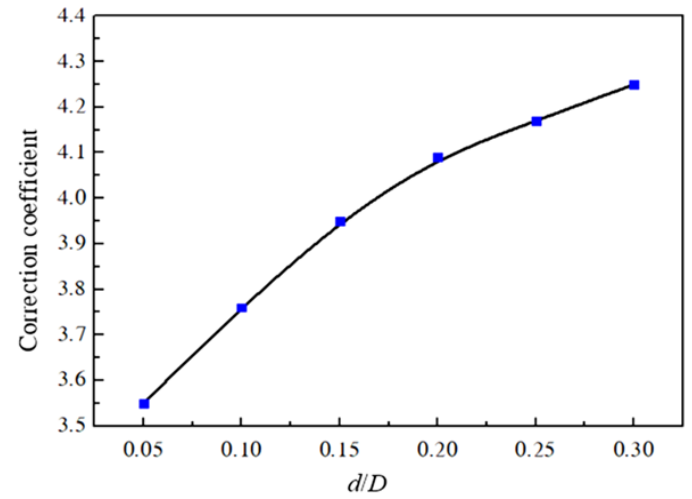

Fig. 3 Relationship curve of correction factor and

The key to full pipe flow delivery is to achieve a balance between the gravitational potential energy and pipeline transportation resistance. By combining the system structural parameters and the calculation formula of the resistance correction coefficient, the total resistance loss $\Delta$ of the HEDDs and the vertical pipe section can be obtained as

$\Delta P=\left[4.82 \frac{H_{1}}{s} \sqrt{(\pi D)^{2}+s^{2}}\left(\frac{d}{D}\right)^{0.1}\right]\left(\frac{16}{3 d} \tau_{0}+\frac{32 v}{d^{2}} \mu\right)$

The total gravitational potential energy of concrete $\operatorname{mortar} \Delta$ is

$\Delta E=\rho \mathrm{g}\left(H_{0}+H_{1}\right)$

The expression of the target safety distance, for the balance between gravitational potential energy and the resistance, is

$H_{0}=\frac{4.82 \sqrt{(\pi D)^{2}+s^{2}}\left(\frac{d}{D}\right)^{0.1}\left(16 \tau_{0}+96 v \mu\right)-3 \rho \mathrm{g} s d^{2}}{3 \rho \mathrm{g} s d^{2}-\mathrm{s}\left(16 \tau_{0}+96 v \mu\right)} H_{1}$ 
As shown in Eq. (9), the rheological and structural parameters considerably influence the safety distance determination. The rheological parameters are density $\rho$, viscosity $\mu$, and yield stress $\tau_{0}$. The structural parameters are the pipe diameter $d$, the pipe and helix diameter ratio , and the pitch $s$.

\section{Results and discussion}

The design elevation of a mine shaft is from 18.5 to $-1540.0 \mathrm{~m}$, the depth is $1559.8 \mathrm{~m}$, the diameter is $8.2 \mathrm{~m}$, and the lining is by C50 concrete. The height of the HEDD is set to $10.0 \mathrm{~m}$ according to the layout of the shaft space, and the calculated Reynolds number is $=9.3<2300.0$. The mortar in the pipe is in a laminar flow state.

\subsection{Structural parameter analysis}

Three structural parameters of the helical pipe, diameter $d$, pipe and helix diameter ratio, and the pitch $s$ are selected for the influence discussion on safety distance $H_{0}$.

\subsubsection{Pipe diameter}

Five pipe diameters, 100.0, 159.0, 180.0, 219.0, and $250.0 \mathrm{~mm}$ are selected for discussion. The helix diameter is $1.0 \mathrm{~m}$, the pitch is $2.00 \mathrm{~m}$, and the average flow velocity is $1.0 \mathrm{~m} / \mathrm{s}$.

The relationship between the safety distance and the pipe and pipe diameter is shown in Fig. 4, which shows that the safety distance is negatively related to the pipe diameter. The safety distance maximum value is $2299.1 \mathrm{~m}$, and the minimum value is $205.0 \mathrm{~m}$. The reason is that the resistance in pipe decreases with the increase in diameter, which requires more dissipation devices to balance the potential energy.

However, when the pipe diameter is beyond $200.0 \mathrm{~mm}$, the influence of diameter on the resistance of the gradually weakens. Moreover, the change range of safety distance slows down. Considering the engineering practice and the standard pipe diameter, the optimal pipe diameter for deep shaft concrete transporting is $219.0 \mathrm{~mm}$.

The safety distance from the numerical simulation is shown in Fig. 4, which shows that the numerical simulation results agree with the HEDPM result. The numerical results are higher than the theoretical results for the simulation accuracy and parameter selection.

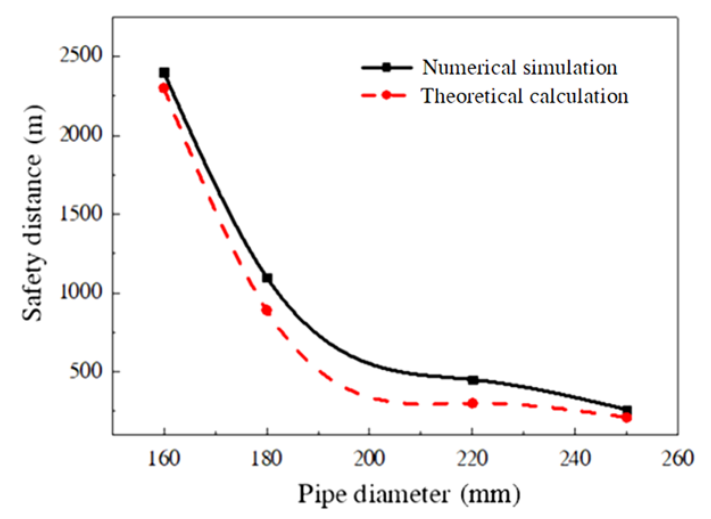

Fig. 4 Safety distance vs. pipe diameter.

\subsubsection{Pipe and helix diameter ratio}

Six helix diameters, namely, 1.0, 1.2, 1.4, 1.6, 1.8, and $2.0 \mathrm{~m}$, are selected for safety distance analysis. The pipe diameter is $219.0 \mathrm{~mm}$, the pitch is $2.00 \mathrm{~m}$, and the average flow velocity is $1.0 \mathrm{~m} / \mathrm{s}$.

The relationship between the safety distance and the pipe and helix diameter ratio is shown in Fig. 5. The figure shows that the safety distance is negatively related to the pipe and helix diameter ratio. The maximum safety distance is $484.6 \mathrm{~m}$, and the minimum value is $286.3 \mathrm{~m}$. The reason is that the helix diameter decreases with the increase in the pipe and helix diameter ratio. The helix angle of HEDD increases, which reduces the secondary flow intensity in the spiral pipe. Thus, the resistance and energy dissipation efficiency decrease with the decrease in safety distance.

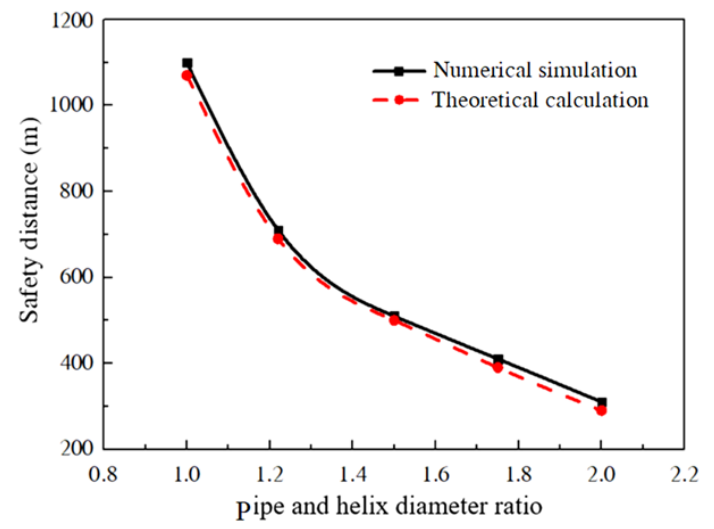

Fig. 5 Safety distance vs. pipe and helix diameter ratio.

The relationship between the safety distance and the pipe and helix diameter calculated by numerical simulation is shown in Fig. 5, which shows that the numerical simulation and theoretical calculation results are consistent. However, the former is larger than the latter.

\subsubsection{Pitch}

Five screw pitches, namely, 1.00, 1.25, 1.50, 1.75, and $2.00 \mathrm{~m}$, are selected for dissipation device distance analysis. The HEDPM input parameters are the pipe diameter of $219.0 \mathrm{~mm}$, the helix diameter of $1.0 \mathrm{~m}$, and the average flow velocity of $1.0 \mathrm{~m} / \mathrm{s}$.

The relationship between the safety distance and the pitch is shown in Fig. 6. The figure shows that the safety distance is negatively related to the pitch and decreases as the pitch increases. In the range of the selected pitches, the maximum value of the safety distance is $1059.2 \mathrm{~m}$ and the minimum value is $286.3 \mathrm{~m}$. The reason is that helix angle increases, the total length of the spiral energy dissipation device decreases, the energy dissipation efficiency decreases, and the safety distance gradually decreases with the increase in pitch.

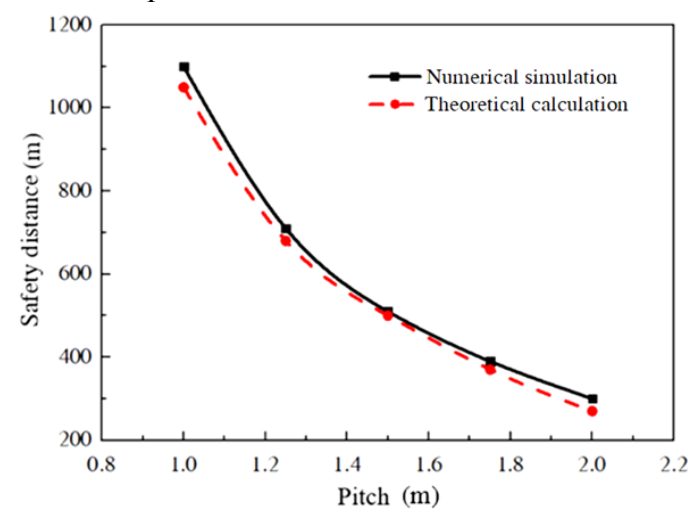

Fig. 6 Safety distance vs. pitch. 
At present, the conveying depth of deep shaft concrete is mainly concentrated in the range of 1000-1500 m. The pitch should be reasonably controlled to prevent the phenomenon of pipe plugging. The size should also be greater than $1.5 \mathrm{~m}$.

The relationship between the safety distance and the pitch calculated by numerical simulation is shown in Fig. 6, which shows that the numerical simulation and theoretical calculation results are consistent. However, the former is larger than the latter.

\subsection{Flow velocity analysis}

Five groups of flow speed, namely, 0.50, 0.75, 1.00, 1.25, and $1.50 \mathrm{~m} / \mathrm{s}$, are selected for comparison and analysis according to the demand situation to analyze the effect of different flow speeds of concrete slurry on the safety distance. The diameter of the concrete transporting pipe is set to $219.0 \mathrm{~mm}$. The helix diameter is set to $1.0 \mathrm{~m}$, and the pitch is set to $2.00 \mathrm{~m}$. The relationship between the safety distance and the flow velocity is shown in Fig. 7.

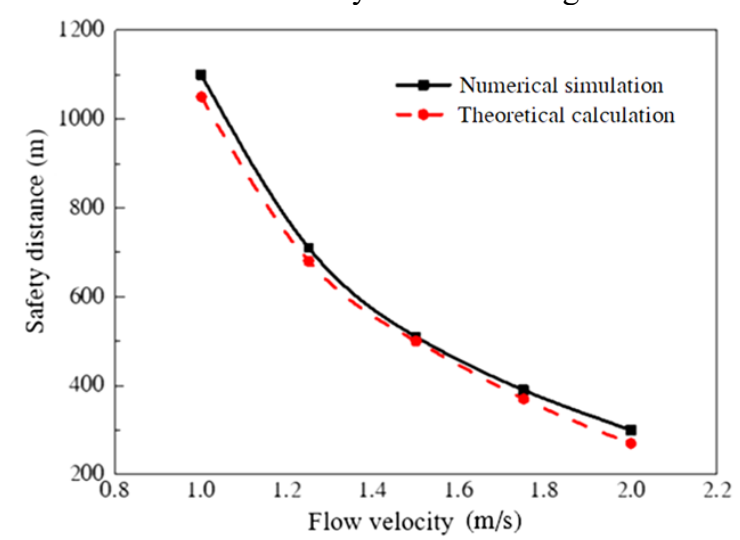

Fig. 7 Safety distance vs. flow velocity.

The safety distance is positively related to the flow velocity. The maximum value of the safety distance is $2042.1 \mathrm{~m}$, and the minimum value is $261.7 \mathrm{~m}$. The reason is that the resistance increases with the increase in flow velocity. As a result, the safety distance increases correspondingly with the increase in energy dissipation efficiency. Higher velocity concrete mortar will increase the scouring frequency on pipe wall, which causes rapid wear. The suggested optimal slurry safe flow velocity after technical and economic comparison is $0.50-0.75 \mathrm{~m} / \mathrm{s}$.

The relationship between the safety distance and the flow velocity calculated by numerical simulation is shown in Fig. 7 , which shows that the numerical simulation and theoretical calculation results are consistent. However, the former is larger than the latter.

\section{Conclusions}

To eliminate the high potential energy of concrete mortar, the HEDD was added in the vertical pipe. Then, the safety distance among the adjacent devices was studied based on full pipe flow theory, and several influencing factors were analyzed. The conclusions are discussed as follows.

(1) Vertical transportation of concrete mortar is essential to the deep shaft lining strength and construction efficiency. The HEDD for mortar's high potential energy control in a vertical pipe of gravity transportation is invented to control the accelerated flow, pipeline wear, and mortar segregation. This study establishes a helical energy dissipation predicting model (HEDPM). The relationship of the safety distance among the dissipation devicess is deduced on the basis of full pipe flow theory.

(2) The correction coefficient is introduced to derive the resistance loss inside the dissipation device, which is verified by the numerical simulation method. The safety distance prediction equation is established on the basis of the energy balance.

(3) The safety distance is negatively related to the pipe diameter, pipe and helix diameter ratio, and screw pitch but is positively related to the flow velocity in a deep shaft case study. The suggested optimal parameters of HEDD by the technical and economic comparison are a screw pitch of more than $1.50 \mathrm{~m}$, a pipeline diameter of $219.0 \mathrm{~mm}$, and a safety flow velocity of $0.50-0.75 \mathrm{~m} / \mathrm{s}$.

The safe distance among the HEDDs for the gravity pipeline transportation design was determined in this study, with the continuous increase of mining depth, the pipeline transportation will become more complicated, so the new challenging design method will be further studied in the future.

\section{Acknowledgments}

This work was supported by the National Key Research and Development Program of China (2016YFC0600802), the National Natural Science Foundation of China (51974135; 51704094), and the Science Fund for Distinguished Young Scholars of Henan Polytechnic University (J2020-3).

This is an Open Access article distributed under the terms of the Creative Commons Attribution License

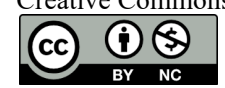

\section{References}

1. Zhao, Y. H., Wang, S. R., Zou, Y. F., Wang, X. C., Huang, B. Q, Zhang, X. G., "Pressure-arching characteristics of fractured strata structure during shallow horizontal coal mining”. Tehnicki Vjesnik-Technical Gazette, 25(5), 2018, pp. 1457-1466.

2. Zhao, X. D., "Basic theory and development trends of ultra-deep shaft construction". Metal Mine, 47(4), 2018, pp. 1-10.

3. Yu, Y.J., Zhu, W. C., Li, L.C., "Simulation on hydraulic fracture propagation of coal-rock combination in deep underground". Hazard Control in Tunneling and Underground Enginering, 1(3), 2019, pp. 96-108.

4. Zhang, X.G., Wang, S. R., Gao, X., "Mechanical properties of recycled aggregate concrete subjected to compression test". Journal of Engineering Science and Technology Review, 11(6), 2018, pp. 20-25.
5. Wang, S. R., Xiao, H. G, Hagan, P., Zou, Z. S., "Mechanical behavior of fully-grouted bolt in jointed rocks subjected to double shear tests". Dyna, 92(3), 2017, pp. 314-320.

6. Zhang, X.G., Wang, S. R., Gao, X., "Mechanical properties of recycled aggregate concrete subjected to compression test". Journal of Engineering Science and Technology Review, 11(6), 2018, pp. 20-25.

7. Kos, Z., Klymenko, Y., Polianskyi, K., Crnoja, A., "Research of the residual bearing capacity and the work of damaged reinforced concrete beams's inclined sections". Technical Journal, 14(4), 2020, pp. 466-472.

8. Zhang, X.G., Kuang, X. M., Wang, F., Wang, S. R.,"Strength indices and conversion relations for basalt fiber-reinforced recycled aggregate concrete". Dyna, 94(1), 2019, pp. 82-87. 
9. Liu, X. H., Wu, A. X., Wang, H. J., "Full-flow transport theory and its application in deep mine backfilling". Journal of University of Science and Technology Beijing, 35(9), 2013, pp. 1113-1118.

10. Zhang, Q. L., Cui, J. Q., Zheng, J. J., "Wear mechanism and serious wear position of casing pipe in vertical backfill drill-hole". Transactions of Nonferrous Metals Society of China, 21(11), 2011, pp. 2503-2507.

11. Cooke, R., "Design procedure for hydraulic backfill distribution systems". Journal-South African Institute of Mining and Metallurgy, 101(2), 2001, pp. 97-101.

12. Hewitt, D., Allard, S., Radziszewski, P., "Pipe lining abrasion testing for paste backfill operations". Minerals Engineering, 22(12), 2009, pp. 1088-1090.

13. Wu, A. X., Liu, X. H., Wang, H. J., Jiao, H. Z., Liu, S. Z., "Calculation of resistance in total tailings paste piping transportation based on time-varying behavior". Journal of China University of Mining \& Technology, 42(5), 2013, pp. 736-740.

14. Zhang, X.G., Wang, S. R., Gao, X., He, Y. S., "Seismic behavior analysis of recycled aggregate concrete-filled steel tube column". Journal of Engineering Science and Technology Review, 12(4), 2019, pp. 129-135.

15. Wang, S. R., Li, C. L., Wang, Y. G., Zou, Z. S., "Evolution characteristics analysis of pressure-arch in double-arch tunnel". Tehnicki Vjesnik- Technical Gazette, 23(1), 2016, pp. 181-189.

16. Kos, Z., Paruta, V., Gnyp, O., Lavrenyuk, L., Grynyova, I., "Designing plaster mortar for a high-rise building". Technical Journal, 13(4), 2019, pp. 331-336.

17. Wang, S., Wu, A., Yin, S., "Influence factors of pressure loss in pipeline transportation of paste slurry". Chinese Journal of Engineering, 37(1), 2015, pp. 7-12.

18. Zhang, L., Ai, W., "Research on energy dissipation characteristics of sudden reduction and sudden enlargement energy dissipater". Water Resources and Power, 36(10), 2018, pp. 123-125.

19. Fossa, M., Guglielmini, G., "Pressure drop and void fraction profiles during horizontal flow through thin and thick orifices". Experimental Thermal and Fluid Science, 26(5), 2002, pp. 513-523.
20. Bullen, P., Cheeseman, D., Hussain, L., "The determination of pipe contraction pressure loss coefficients for incompressible turbulent flow". International Journal of Heat and Fluid Flow, 8(2), 1987, pp.111-118.

21. Wu, A., Cheng, H., Wang, Y., Wang, H., Liu, X., Li, G., "Transport resistance characteristic of paste pipeline considering effect of wall slip". The Chinese Journal of Nonferrous Metals, 26(1), 2016, pp. 180-187.

22. Li, H., Wang, H., Wu, A., Zhong, S., Liu, X., Jiao, H., "Research on waste of Ge for paste theological properties and gravity transport law". Journal of Wuhan University of Technology, 34(12), 2012, pp. $113-118$

23. Jiao, H., Liu, C., Wu, A., "Effect of initial turbulence intensity and rake shear on Flocculation Behavior of tailings". Engineering Science and Technology, 52(2), 2020, pp. 54-61.

24. Wang, Y., Jiao, H., Li, Z., "Strength and damage characteristics of white sandstone under unloading confining pressure". Journal of China Coal Society, 45(8), 2020, pp. 2787-2794.23.

25. Liu, Z., Xiao, S., Wang, W., "Pipeline transportation of backfilling slurry with high filling times line and strong resistance in undersea mining". Transactions of Nonferrous Metals Society of China, 26(8), 2016, pp. 1802-1810.

26. Jiao, H., Han, Z., Chen, X., "Toughness evolution law of basalt fiber shotcrete based on NMR technology". Journal of China Coal Society, 44(10), 2019, pp. 2990-2998.

27. Ali, S. "Pressure drops correlations for flow through regular helical coil tubes". Fluid Dynamics Research, 28(11), 2001, pp. 295-310.

28. Santini, L., Cioncolini, A., Lombardi, C., "Two-phase pressure drops in helically coiled steam generator". International Journal of Heat and Mass Transfer, (19-20), 2008, pp. 4926-4939.

29. Zhou, H., Xie, H., Dong, Z., "Support technique of steel fiber shotcrete for soft rock tunnel at great depth". Journal of Engineering Geology, 9(4), 2001, pp. 393-398.

30. Jiao H., Wang, S., Wu, A., "Cementitious property of NaAlO2activated Ge slag as cement supplement". International Journal of Minerals, Metallurgy and Materials, 26(12), 2019, pp. 1594-1603. 